\title{
RESULTS OF REHABILITATION IN CENTRAL CORD SYNDROMES
}

\author{
By E. Berard, M.D., P. Minaire, M.D., R. Girard, M.D. and Professor J. Bourret ${ }^{1}$ \\ Department of Spinal Cord Injuries, Hôpital Henry Gabrielle, \\ Route de Vourles, F69230 Saint-Genis-Laval, France
}

Abstract. Out of 180 cervical cord syndromes (traumatic, neoplasic and vascular) studied we examined the prognosis of rehabilitation in 3I central cord syndromes dating back from 6 months at the least or 6 years at the most.

Key words: Rehabilitation.

Is it better to have functional lower limbs or an adequate arm capability? That is the question.

\section{Material and Methods}

We have studied 3 I cases, Io female patients and 2 I male patients, 3 of whom were old enough to retire. We have examined both our documents and the answers given by the patients to the following standard list of questions on their background: (I) the functional abilities, such as walking, the activities of daily living, independence and driving; (2) pain and the trophic disorders; (3) the means of living; (4) the familial dependencies: husband or wife and children; (5) the conditions for returning home and the requirements of the patients; and (6) entertainments and going out.

\section{The Functional Abilities}

\section{Results}

At first sight, such a partial syndrome should impress us; for instance in our study 27 out of 3 I patients were able to walk again without a stick. However, such abilities are jeopardised by the awkwardness and partial paralysis of the hands, and the inability to grasp anything. This disability is permanent because of motor and trophic disorders in 29 cases out of $3 \mathrm{I}$, including the symptoms of stiffness, painful osteoporosis, spasticity. Only I 7 cases out of the $3 \mathrm{I}$ were able to dress themselves without assistance, 20 able to wash themselves, and 26 to cope with cooking, housework and shopping. In 23 cases, patients travel by a car driven by an attendant, and in only 6 cases could patients use public transport. The urinary problems are not caused by a vesico-sphincterial dysfunction but just by a disability to dress and undress themselves. That functional impairment of their arms can often hinder patients from working again.

\section{Professional Occupation}

Apart from the retired patients, we have only recorded 8 patients who could return to work. Those cases corresponded to a combination of the best functional recovery and a pressing financial need. Among the female patients, 3 could do their housework again but even so, they had to be helped.

\footnotetext{
1 Paper read by Dr. E. Berard, from whom offprints may be requested.
} 


\section{Financial Support for Living}

In 18 cases financial support arises from allowances for disability or industrial injuries, and, in $\mathbf{2} 2$ cases, increased allowances for a permanent attendant. As for the remaining patients, they all benefit from capital which is either their own or given by the insurance of a responsible third party, or they benefit from their husband's or wife's means.

The French system suppresses a part of those disability allowances as soon as the patient returns to work, which could explain that few of them do it.

\section{Home and Family Situation}

Moving home is infrequent (4 cases out of $3 \mathrm{I}$ ), for accessibility is possible even for the patients living on an upper floor without a lift as they can all walk.

Their family situation remains unchanged in most cases after the handicap: only two patients have married and one man has divorced. That man had become irreversibly impotent after his handicap.

Due to this familial stability, the husband or wife of the patient can act as the permanent attendant and can help him in the activity of daily life. As for the unmarried patients, most of them are helped by their parents who care for their dependence well enough not to require their settlement in a special centre for highly disabled patients.

\section{Going Out and Entertainments}

Patients go out by car every day in 20 cases out of $3 \mathrm{I}$, but most of them depend on a driver to do so. Only one patient practises a sport (skiing), and he had had a recovery rate of better than 50 per cent. Entertainments are within the family rather than collective, and here once more is the manifestation of the functional constraint of the arms.

\section{Discussion}

In spite of the recovery of the lower limbs for walking, the functional abilities of patients with spinal cord syndromes are not as good as the abilities of paraplegic patients, even complete ones, because of the functional impairment of their upper limbs which makes them similar to tetraplegic patients. We can easily realise that the professional prognosis for such patients is worse than in the cases of complete thoracic or lumbar cord injuries.

For the assessment of social compensations one must first of all take into account the fact that such patients are just as dependent as tetraplegic patients before deciding what the state of their disablement is, or the increased allowance for a permanent attendant.

Let us also compare their possibilities of family rehabilitation with those of paraplegic patients. We realise that things are not so difficult for paraplegics, because they can walk upstairs and clear all sorts of obstacles more easily. Conversely, as for their going out and entertainments, we witness again the impediment set up by the functional loss of their arms which deprives them of the entertainments, sports, and social contacts that paraplegic patients retain. 


\section{SUMMARY}

The study of 3I cases of central cord syndromes has shown that the results of rehabilitation were more unsuccessful for these patients than for paraplegics.

In spite of a good recovery of the functions of their legs they constantly come up against a functional loss of their arms which hinders their house activities so that most of them require help and can also hinder their social contacts.

\section{RÉSUMÉ}

L'étude de trente et un cas de syndromes centromédullaires a permis de montrer que la réadaptation était moins réussie chez ces patients que chez les paraplégiques dans les atteintes médullaires dorso-lombaires. En dépit d'une bonne récuperation fonctionnelle des membres inferieurs, l'atteinte de leurs membres superieurs les gêne dans leurs activités domestiques et leurs contacts sociaux.

\section{ZUSAMMENFASSUNG}

In 3I Fällen von centralen cervical injuries erlaubten die entsprechenden Beobachtungen zu beweisen dass eine Wiederherstellung dieser Art von Patienten nicht so gunstig is als in Fällen von Rückennmarkschädigungen der thorakalen und lumbalen Regionen.

Trotz einer günstigen Wiederherstellung der Beine, stört die Obschädigung der oberen Extremitäten ihre häusliche Tätigkeit und noch mehr ihre menschlichen sowie gesellschaftlichen Verbindungen.

\section{General Discussion}

DR F. W. MeINECKe (Germany). I have two questions for this speaker. First of all the title is Prognosis of Central Cord Syndromes but you gave us only the results, and I would like to hear some words about the acute stage of these patients. The second question is I wonder why you have in your series 17 people dressing themselves and 23 depending on a driver by car. I can't see the point why so many of them need a driver or are depending on a driver if they are able to dress themselves.

DR E. BERARD (France). I did not understand the first question. I'm sorry.

DR MEINECKE. The first question was the title of your paper was Prognosis in Central Cord Syndrome, but what we saw on the figures were end results, the results at the end of the rehabilitation. I would like to have some idea of what was the acute stage, to appreciate what is the prognosis.

DR E. BERARD. For the first question we can say prognosis after our experience in 7 years when we see our next central cord syndromes with a good recovery of their legs we must say that the prognosis is not quite good. They are not able to drive a car but they are able to dress or undress themselves because to drive a car in France authorities are very strict on giving a driving licence and so they cannot drive any car because they are not allowed to do so. 